\title{
Investigation and Research on the Construction of Foreigners' Helper Station in the Background of "Internet +"
}

\author{
Sha Wang ${ }^{1, \text { a }}$ Yongjun Wang ${ }^{2, b}$ \\ ${ }^{1}$ Nanjing Institute of Industry Technology, School of Business and Economics, Nanjing, Jiangsu, \\ China, 210000 \\ aemail, bemail,
}

Keywords: Internet+, Foreigners, Helper Station

\begin{abstract}
Based on the "Internet plus", this paper analyzes the problems foreigners met in Nanjing. At the same time, this article investigates the feasibility of the 'Foreigners Help Station' . According to the results of investigation, foreigners would welcome "Foreigners Help Station" if the station could provide excellent services.
\end{abstract}

\section{Introduction}

"Internet + " is the social field and the development of the Internet results of the superposition and integration, resulting in a new mode of operation to promote the industry's progress and promote innovation and development. Foreigners living assistant workstations are established in the context of "Internet +", with the Internet age and the arrival of the global village era, the number of foreigners entering China is increasing year by year. Nanjing resident foreign population has reached 18,000 people, language problems become foreigners in China encountered a major problem.

Therefore, this article will be from the "Internet +", workstation industry development and prospects analysis of the feasibility of foreign workers living assistant workstation.

\section{The Summary of "Internet +"}

The Provision of "Internet +". January 22, 2016, China Internet Information Center CNNIC today released the 37th "China Internet Development Statistics Report". The report shows that as of December 2015, the size of Chinese Internet users reached 688 million, the Internet penetration rate of $50.3 \%$; mobile Internet users reached 620 million scale, accounting for $90.1 \%$, significantly improved wireless network coverage, Internet users Wi-Fi usage 91.8\%. Compared with the end of 2014 it enhances the 2.4 percentage points. Now, half of the Chinese people have access to the Internet, Internet users to increase the scale of growth, while Internet users personal Internet equipment to further focus on the mobile phone.

The Connotation of "Internet +". The meaning of Internet + is to give full play to the optimization and integration of the Internet in the distribution of production factors, the Internet's innovative achievements and economic and social areas of deep integration, resulting in chemical reactions, amplification effect, and vigorously enhance the real economy innovation and productivity, The formation of a wider range of Internet-based infrastructure and the realization of new forms of economic development

The Development of "Internet +". In recent years, it got the rapid development of the Internet in the country. According to the Ministry of Industry and Information Technology, from January to March 2015, the three basic telecommunications enterprises Internet broadband access users a net increase of 1.372 million, a total of 2.04 million; in January 2015, Chinese total number of mobile phone users reached 1.29 billion, The total number of mobile Internet users increased by more than 24 million, the total size of nearly 900 million, an increase of 5.7\%; the number of users using mobile Internet users a record high, the total number of 858 million, the penetration rate of mobile phone users reached $66.3 \%$ over the previous year to enhance 1 percentage point. The Internet has 
partially changed Chinese economic structure and industrial structure, giving birth to a number of new business models, such as e-commerce, mobile payment, Internet communications and online education.

The service providers rise of "Internet +". At present, "Internet +" has emerged a large number of third-party service enterprises between government and enterprises, which themselves will not engage in the production, manufacture and operation of Internet + traditional enterprises, but they will help both online and offline of the cooperation, profitability is the two sides after the success of the service costs and a variety of value-added services costs.

\section{The Feasibility of the Construction of Foreigners Help Station}

Chinese Foreign Population. As the world's first trading power, the second economic power, and now Chinese cross-border population inflow range has been considerable. Such population inflows are reflected in the growing number of foreign tourists on the one hand. Between 2006 and 2011, the number of foreign tourists entering mainland China increased from 22.21 million to 27.112 million. On the other hand, Chinese resident foreigners are also increasing. According to the results of the 6th census, with the time of November 1, 2010 as the standard time, living in our territory and accept the census registration of foreigners 593832 people, close to 600,000

Recent Developments and Trends of Foreign Personnel Life Assistant Station. Internet + era background, for foreigners to provide convenient services more and more information, diversification, personalized. Throughout the current research situation and achievements in this field at home and abroad, foreign research content and technology are relatively mature, such as in Singapore, to help the Chinese organization in the form of community association. In the United States, there are Los Angeles Chinese information network, the information network for the Chinese to provide news, tourism, culture and other services. Throughout the domestic market, this area of research and market operations was weak.

According to statistics, Nanjing Public Security Bureau Exit-Entry Administration Department of the data show that 2015, Nanjing, foreign residents about 18,000. These foreigners live, work, live in Nanjing, in all aspects will encounter language communication, social understanding and other difficulties. For example: foreign friends in medical treatment, the major hospitals in Nanjing strong department do not understand, do not understand the process of medical treatment. Some foreign friends spend a lot of energy, see the doctor, but cannot communicate with the doctor; in the shopping, many friends want to buy Nanjing cultural characteristics of the specialty, what to buy, pick what brand, where to buy but become a In the traffic, dining, the domestic taxi now, ordering the use of mobile APP, and to fill in the specific address on the APP, or the taste of dishes. This APP mostly for the Chinese interface, not only to read Chinese, but also to enter the Chinese, foreigners cannot use the basic, in terms of culture, foreigners living in Nanjing, but nowhere to experience the traditional Chinese culture, no guidance.

On the whole, with the deepening of Chinese internationalization, the number of expatriates entering China has been increasing year by year and the market potential of the source market is large, while the companies, institutions and groups interested in this market are not many. Therefore, to provide them with a variety of personalized convenience needs, to solve their problems encountered in the country, has become the foothold of the project.

Research Methods. Interview: The project intends to interview more than 100 expatriates and more than 100 students to understand the feasibility of the market;

Questionnaire survey: This project will provide two questionnaires to expatriates and students in order to study the supply and demand of service. This topic interviewed more than 100 expatriates from Nanjing Xianlin University City and found the questionnaire the needs of expatriates and the form of demand help, acceptable fees and so on. This course interviewed more than 100 students from the South Institute of Work, through the questionnaire to find out how many students are willing to provide services to foreigners, service forms, and service fees. Field interviews and questionnaires for expatriates (Table 1) were conducted from October 2016 to October 20, 2010, and 105 foreigners from 11 countries were investigated to investigate the presence of expatriate 
demand markets, foreigners whether they are willing to accept the help of college students as the main body and other issues. Among the 105 respondents, 46 were male, 59 were women, aged 15 to 20, aged 20-35, aged 30-50, aged 2 and above; In 2 years of 33 people, 2-5 years 44 people, 5-10 years 14 people, more than 10 years 14 people. Among the 105 people, 49, about 47\% of the respondents have a master's degree or higher; of which 86 , about $82 \%$ of the respondents are basically no Chinese knowledge; 61 people, about 58\% there is a demand. There are 99 people, about $92 \%$ of the respondents are willing to accept APP services; 80 people, $77 \%$ of respondents are willing to accept hourly billing, 58 people, 55\% of respondents accept 15-20 per hour The price of RMB; 93 people, about $89 \%$ of the respondents are willing to accept the help of college students. The questionnaire has a total of 13 questions, as shown in Table 1.

\section{Table 1 Questionnaire}

1、 What is your gender?

2、 How old are you?

3、 which country do you come from?

4. How long have you been in China?

5. What's your highest degree?

6、 Can your Chinese language skills solve your daily problems?

7、In which aspects do you need help?

8、If there is a platform(APP) can help you solve daily problems, are you willingto use it?

9、What are your concerns about the platform (APP) ?

10、 Which way of payments would you choose?

11. How much can you accept charged by the hour?(CNY)

12、Whether you will choose college /university students to help you?

13、 Why?

ROST word frequency analysis: the project in the conduct of a questionnaire survey, and later in the recording material for the text material, so the use of ROST word frequency analysis, to identify the two sides of the service supply and demand of common concern.

Research Ideas. The project uses field interviews, questionnaires, data analysis methods, analysis of Nanjing Xianlin University City to help foreigners.

Results of the Study. 100 people are willing to use the number of foreigners living assistant station number 87 from the results can be seen, foreigners life assistant station is still very strong and the market prospects are huge.

Foreign Staff Life Assistant Station SWOT Analysis

Located in Nanjing, Jiangsu Province, the huge potential for consumption.

$\checkmark$ Innovative, innovative, through the "Internet +" way to provide intimate car service.

- Nanjing is currently no foreign staff life assistant station function of various workstations.

- Nanjing Xianlin campus is far away from the urban area, the site rent is relatively low, open foreign staff life assistant station of the lower cost, you can save money into the decoration, improve equipment quality and enhance their competitiveness.

- Foreign staff life assistant station services in all directions, to meet the needs of modern life.
The strength of college students' entrepreneurial economy is limited

$\checkmark$ Insufficient management experience

- Foreign staff life assistant station services in the early need to invest a lot of manpower and resources

- The obstruction of the idea Lack of experience in market development 


\begin{tabular}{|c|c|}
\hline $\begin{array}{l}\text { College students' business loans and } \\
\text { preferential policies. } \\
\text { The school offers business space and } \\
\text { platform. }\end{array}$ & \\
\hline $\begin{array}{l}\text { Government support, provision of loans } \\
\text { and policy support. } \\
\text { Strong social needs. } \\
\text { Lack of professional services. } \\
\text { National innovation } \\
\text { entrepreneurship policy support. } \\
\text { Have a group of passionate } \\
\text { entrepreneurial team. }\end{array}$ & $\begin{array}{l}\text { Easy to be imitated by } \\
\text { competitors } \\
\text { The involvement of other } \\
\text { expatriate life assistant posts }\end{array}$ \\
\hline
\end{tabular}

Countermeasures. We can help with entrepreneurial loans and get angel investment as much as possible for the advantage of limited foreign economic service. Mainly enjoy the relevant policies of small secured loans. Graduates who have graduated within two years of college and technical school graduates may apply for a small secured loan. The loan term for a small secured loan is 1 to 2 years. If the project is well run and there is sufficient capacity to repay the interest, you can apply for a one-year extension. In addition, you can apply for angel investment, the introduction of social and financial forces.

In view of the lack of experience of the operator, on their own, our team itself is a learning organization, to organize innovation and entrepreneurial knowledge and success stories. At the same time, in our entrepreneurial process, encounter problems, will be the school, the teacher's support. Of course, members of the internal communication between the exchange is also essential factors. In addition, because the team members are students, students friends resources are more adequate, you can promote each other, enhance the visibility, increase the consumption channels.

In the face of easy competitors to imitate this situation, we will pre-designed to respond to their competitive strategies, such as: the development of a variety of services to foreigners to improve the service attitude of the service station.

In short, the workstation will be committed to understanding customer needs, providing high quality services to meet customer need to solve foreigners in China encountered problems. In the provision of services for foreigners provide contact with the community, the opportunity to serve the community.

\section{Conclusion}

According to the results of the current survey, the project has a large market potential, a large number of foreigners living in Nanjing, in transportation, medical and other aspects, do encounter a variety of problems, need help. And the school students, as fresh blood into the community, by the trust of foreign friends, and is considered in the intellectual and logical aspects, have the ability to provide help.

Therefore, the project will continue to interview more expatriates, and after receiving the results of interviews with foreigners demand, to promote the supply of services for college students, so as to develop both sides of the market supply and demand. And in the market demand, the specific direction of service builds specific content of the site or APP platform.

\section{Acknowledgements}

Fund Project: 1. 2017 Jiangsu Provincial Project—College students innovation project: Investigation and Research on the Construction of Foreigners' Helper Station in the Background of "Internet +"

2. 2016 Nanjing Institute of Industry and Technology Colleg level project: Investigation and Research on the Construction of Foreigners' Helper Station in the Background of "Internet +" (YK16-07-04) 3. 2016 Industry and Technology College School of Business and Trade of Nanjing 
Institute, School Level Project : Investigation and Research on the Construction of Foreigners' Helper Station in Xianlin Campus in the Background of "Internet +"

\section{References}

[1] Chen Hui. Che Hongsheng cross-cultural adaptation of the factors that review the progress of psychological science, 2003 the first 11

[2] Chen Hui. Chinese students social and cultural adaptability of social psychology research Journal of Beijing Normal University Social Science Edition, 2003 the sixth period

[3] Chen Hui. Students in Beijing to adapt and its influencing factors in Beijing Normal University doctoral dissertation, 2004

[4] Yang Hong. Search engine marketing problems and development [J] Jilin Agricultural C, 2010 tenth issue 